\title{
Exploration of tight oil resources based on stratigraphic paleo-tectonics during hydrocarbon generation in the Ordos Basin, China
}

\author{
Gao Shengli ${ }^{1} \cdot$ Yang Jinxia ${ }^{2}$
}

Received: 7 December 2018 / Accepted: 16 May 2019 /Published online: 13 June 2019

(C) The Author(s) 2019

\begin{abstract}
For many years, oil resource exploration has emphasized the current structural characteristics of potential oil-bearing formations. The traditional view of the Ordos Basin has been that the slope in northern Shaanxi is a gentle westward-dipping monocline that lacks structural traps, such as anticlines. Therefore, it was assumed that structural factors could exert no control over the formation and distribution of the oil reservoirs in the Yanchang Formation. By modeling the evolution and structure of a target layer in the Chang- 8 reservoir during its hydrocarbon accumulation period, combined with a comprehensive analysis of the distributional characteristics of the Chang- 8 oil reservoir, we found a strong link between paleo-slopes and paleo-highs in the target layer and the modern distribution of tight oils. The paleo-structural characteristics of the target layer clearly exhibit control over the Chang8 reservoir. We have proposed a new understanding and method for tight oil exploration, which is based on the recovery of the paleo-geomorphology of the target layer during the hydrocarbon generation period. It incorporates a number of key controls over tight oil accumulation and represents an evolution in the mindset suggested for tight oil exploration in the Ordos Basin.
\end{abstract}

Keywords Paleo-tectonics $\cdot$ Paleo-high $\cdot$ Chang-8 oil reservoir $\cdot$ Tight oil distribution $\cdot$ Ordos Basin

\section{Introduction}

Until recently, researchers have focused on the present-day tectonic features of the Ordos Basin, believing that the North Shaanxi Slope is a gentle westward monocline that features a simple structure and a lack of structural traps for hydrocarbons, such as anticlines. The formation and distribution of reservoirs in the Yanchang Formation are generally considered to be controlled by sedimentary facies, while tectonics and other factors have little effect on the formation and distribution of reservoirs (Yang et al. 2007; Yang et al. 2013b). With the recent increase in drilling density in the region, the uplift structures of the Yanchang Formation-especially low-

Editorial handling: Santanu Banerjee

Gao Shengli

gshl@xsyu.edu.cn

1 School of Geoscience and Engineering, Xi'an Shiyou University, Xi'an 710065, Shaanxi, China

2 School of Mathematics and Information Science, Shaanxi Normal University, Xi'an 710119, Shaanxi, China amplitude, nose-shaped uplift structures-have been recognized as important controls on the formation and enrichment of Triassic reservoirs (Zhao et al. 2006).

With the rapid exploration of tight oil resources in the Ordos Basin, the discovery of the Chang- 6 reservoir in the Huaqing Area has forced researchers to acknowledge the controlling influence of structural factors (e.g., the lake basin bottom configuration) on reservoirs. The Chang- 6 target formation was deposited in a deep-to-semi-deep lake environment. According to conventional exploration theory, this area is a "forbidden zone" for the exploration of tight oil resources. However, studies suggest that the deposition stage of the Chang-6 oil-bearing formation in this area was characterized by the large-scale development of deltas. Large, lowpermeability reservoirs were formed under the joint control of favorable sedimentary facies and diagenetic facies. Due to the lake basin bottom configuration, which featured multiple slope breaks, the tectonic conditions were available for the formation of large, low-permeability reservoirs (Yang et al. 2012; Cai et al. 2015). Therefore, it is believed that the combination of the Ordos Basin delta and gravity flow resulted in sand control conditions during the deposition of Chang-7 and Chang-6 oil-bearing members of the Late Triassic Yanchang 
Formation. This resulted in the formation of a large area of thick, deep-water sandstones in the middle region of the lake basin. Subsequent tectonics controlled the formation of a large area of deep-water sags, a change in the sedimentary systems, the migration of the basin depocenter, and the occurrence of sediment gravity flow events (Yang et al. 2013a).

With the discovery of the Chang-7 tight oil reservoir, located in the Longdong region of Ordos Basin, researchers began to recognize the control exerted by the configuration of the lake basin bottom on tight oil accumulations. In response, additional exploration was targeted at finding tight oil resources in the "deep-water region." This real-world exploration was supported by simulation experiments that studied the gravity flow deposition mechanism (Yang et al. 2015; Liu et al. 2015).

The new emphasis on the important role of structural factors in tight oil accumulation has made it possible to directly find and evaluate tight oil "sweet spots," even though the current focus is only on the morphological characteristics of stratigraphic tectonics. The old theory recognized two major factors that controlled the formation of "sweet spots" within shale formations: the maturity of the deposit, which largely controls the distribution of liquid hydrocarbons, and the definite geostructural background and fluid mobility of the liquid hydrocarbons (Yang et al. 2015). The latter is advantageous to the long-term accumulation of hydrocarbons and the development of natural fractures, and has garnered the most attention under the current economic and technical conditions at home and abroad.

Tight oil reservoir conditions have been a consistent focus of research for decades. In the USA, one of the key priorities considered when determining the feasibility of mining is the superiority of a reservoir's conditions. However, certain structural conditions are necessary for the formation of highquality reservoirs. The edge of a depocenter (or "subsag"), the foreslope of a paleo-highland, and the edge of a paleouplift zone in a lake basin, etc. are structural conditions associated with the formation of high-quality reservoirs; however, this knowledge did not attract extensive attention to the Ordos Basin until the past few years. Presently, the literature on the paleo-tectonic features of geological strata during hydrocarbon generation is very weak, and quantitative research is particularly sparse. The reconstruction of paleo-tectonic morphology still operates on the basis of traditional sedimentary facies analysis, which outlines the paleo-tectonic framework (Zhao et al. 2003; Guo et al. 2010; Li and Wen 2017). The Mesozoic Ordos Basin was a lake basin characterized by sags in a stable craton. It has been difficult to fill in important gaps in our knowledge about this basin, such as the characteristics of its paleo-structural morphology and depositional slopebreak zones during the hydrocarbon generation period. Most efforts have been hampered by their reliance on the stratigraphic filling structure and configuration revealed by the current lithostratigraphic unit, as well as the monotonous, near-parallel stratigraphic structure reflected by seismic data. By contrast, a basin simulation approach provides an efficient way to quantify the paleo-tectonic conditions and the evolution of the lake basin (Tong and Mukerji 2017; ClaveraGispert et al. 2017). The approach described in this study could facilitate research into the relationship between the lake basin bottom configuration and the development of a highquality reservoir, as well as the genesis and distribution of high-quality reservoirs, more generally.

Most researchers believe that basin source rocks were subjected to at least three periods of hydrocarbon charge and accumulation (Luo et al. 2016; Li and Wen 2017; He et al. 2017; Lei et al. 2017). During the evolution of the Yanchang Formation, the tight oil charge and hydrocarbon generation period took place from the early Late Jurassic to the late Early Cretaceous (Yang et al. 2013b; Xu et al. 2017). The formation of the main pools took place during the Early Cretaceous, when the strata reached their greatest burial depth (Yang et al. 2013b; Ren et al. 2017). Tectonic uplift began in the Late Cretaceous.

\section{Regional tectonic background}

The Ordos Basin is located in the central and western regions of China (Fig. 1(b)) and covers an area of $25 \times 10^{4} \mathrm{~km}^{2}$. It echoes the Jinxi Fault-fold Belt and Lüliang Uplift in the east and the Liupan Mountain and Yinchuan Basin, through the thrust belt, in the west. The southern boundary follows the Weihe Basin along the Weibei Fault-fold Belt and the north borders the Hetao Basin across the Wulangeer Bedrock Swell. On the whole, this is a N-S-trending rectangular basin with asymmetric megasynclines marked by broad and gentle eastern wings and steep and narrow western wings.

The basin is divided into six first-order tectonic units: the central Yishan Slope, the eastern Jinxi Fault-fold Belt, the western Tianhuan Depression, the western marginal thrust belt, the northern Yimeng Uplift, and the southern Weibei Uplift (Fig. 1(a)). The marginal faulted folds are well developed, while the internal structure is relatively simple (Zhang et al. 2017; Zhu et al. 2018), featuring strata with gentle dips less than $10 \mathrm{~m} / \mathrm{km}$, in general (Figs. 1(c) and 2). No secondorder structure is present within the Yishan Slope, and thirdorder structures are mainly nose-like folds. There are a few high-amplitude anticlines that are well-trapped. The Chang- 8 oil-bearing member is one of the major oil reservoirs in the Triassic Yanchang Formation in the Ordos Basin. Stratigraphically, the Yanchang Formation is divided into five members according to its sedimentary sequence (T3Y1T3Y5), and it has also been divided into ten oil reservoirs, from top to bottom, according to their longitudinal distribution: Chang-1 through Chang-10. Of these reservoirs, Chang- 
Fig. 1 Location of the Ordos Basin in China (a). Tectonic units in the Ordos Basin (b). Well connection stratigraphic correlation profile of Y108X5001 (c)
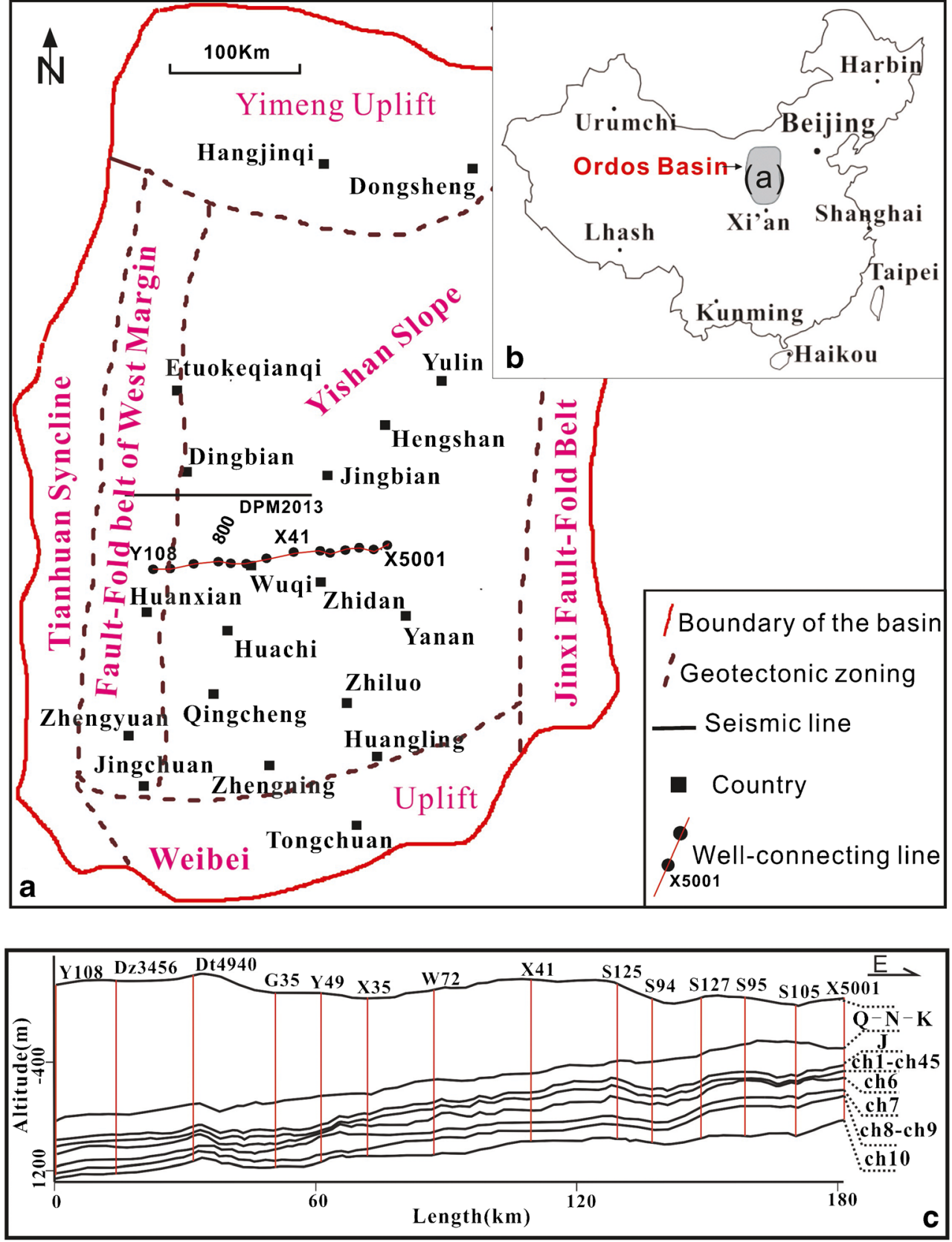

1, Chang-2, Chang-3, Chang-6, and Chang-8 are regional commercial oil reservoirs (Fig. 3).

\section{Methods and materials}

We reconstructed the single-well stratigraphic burial history and the hydrocarbon generation history of the Chang- 8 reservoir using Genex Burial History Reconstruction software (Beicip/IFP). We expanded upon this by using TemisFlow basin modeling software (IFP) to recreate the structure and evolution of two target formations in the Chang- 8 after the hydrocarbon generation period.
We systematically organized data, such as structure, sedimentation, mud logging, and well logging results, in the research area. These data were combined with the ancient landform, the restoration of the denuded formation thickness, and the coefficient of consolidation. The basin was then geologically modeled with selected simulation parameters and defined initial and boundary conditions. This provided the basis for reconstructing the evolution of the basin and the history of its fluid dynamics. At the same time, we used the distribution characteristics of the Chang- 8 reservoir to study the control exerted by the underlying paleo-tectonics and the evolution of the target formation on the development of tight oil. 


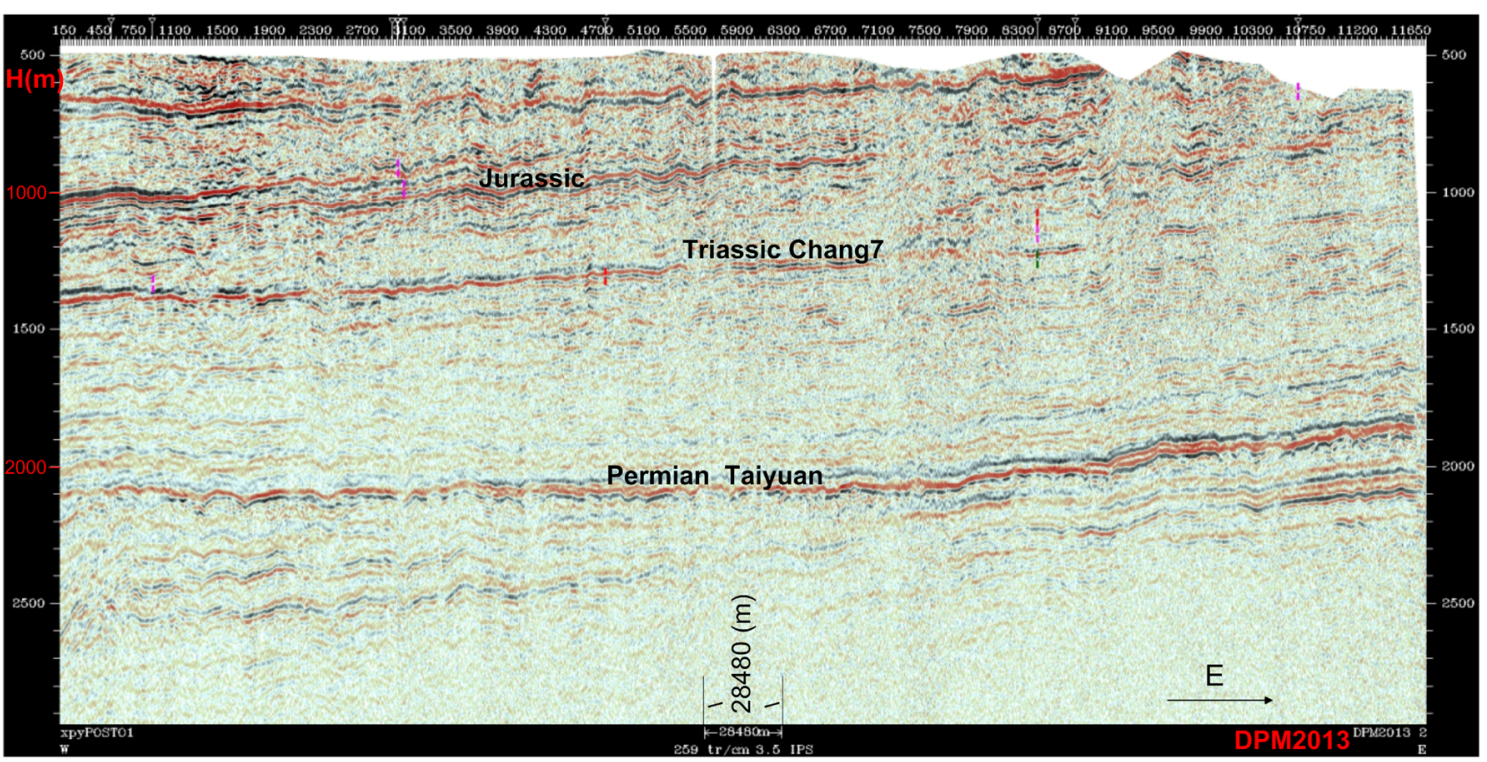

Fig. 3 Formation table and comprehensive stratigraphic column of the Triassic Yanchang Formation in the Ordos Basin

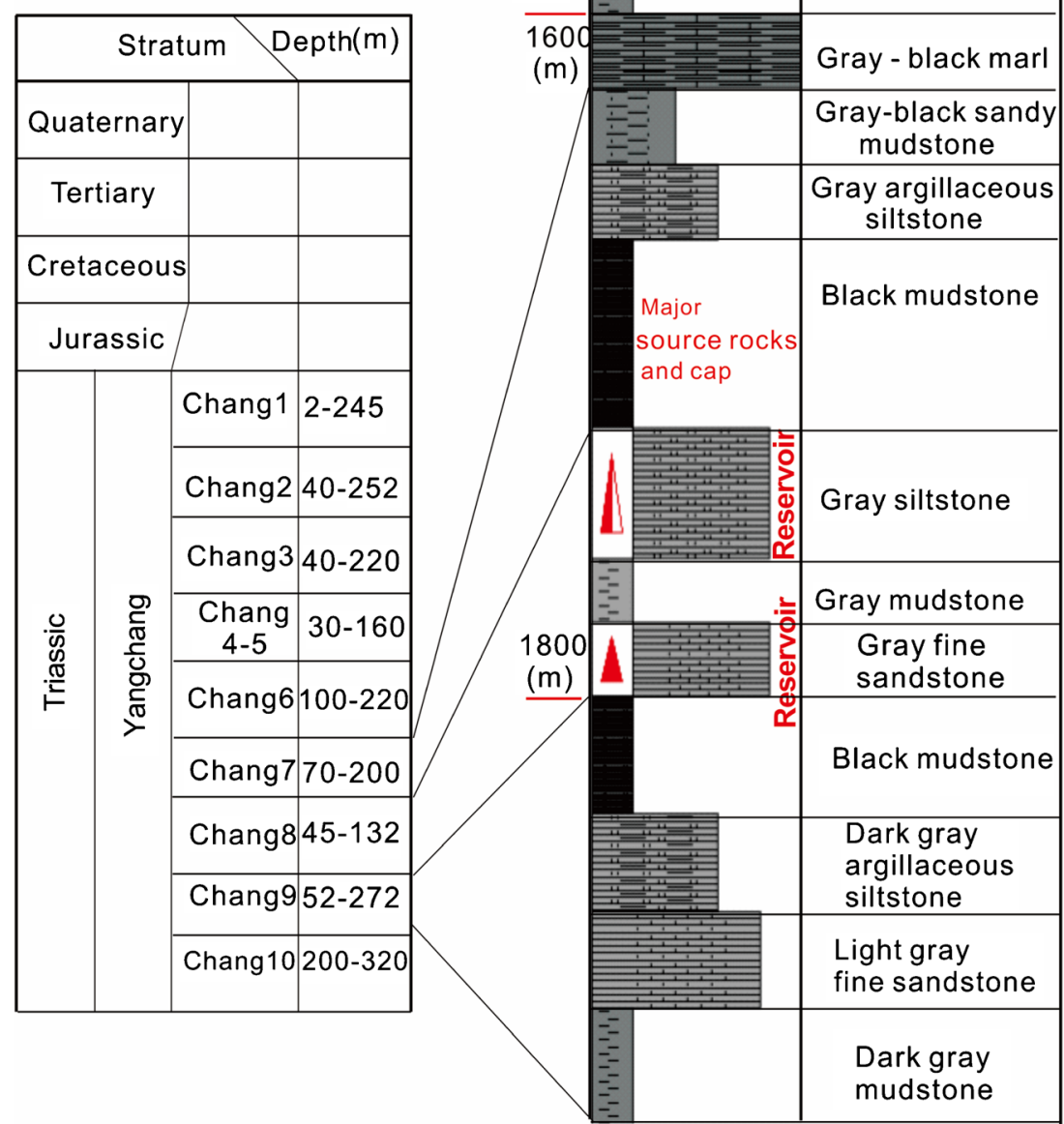


The main parameters involved in the TemisFlow reconstruction of the paleo-tectonic evolution of the Chang- 8 included a mudstone compaction coefficient, denuded strata thickness restoration values, formation thickness, sandstone:formation ratio, and top structure characteristics, etc. The values of these parameters were derived from data taken from a large number of exploratory well logs in the research area. The mudstone compaction coefficient and denuded strata thickness restoration were obtained by interval transit time curves; the formation thickness, sandstone:formation ratio, and top structure characteristics were obtained through the integrated application of well logs, including interval transit time, resistivity, and density. Other simulation parameters included hydrocarbon generation kinetics parameters and temperature field parameters. The latter were based on results from numerous studies of the geothermal field and its evolution in the Ordos Basin.

The underlying paleo-tectonics of the Chang- 8 target formation, and its evolution, were revealed by reconstructing its bottom structure and evolutionary laws after the hydrocarbon generation period. Additionally, the distribution patterns of the Chang-8 tight oil reservoir were explored.

Logging data (mainly interval transit times) were used to calculate formation paleo-pressures by the equilibrium depth method. The sandstone:formation ratio was determined based on basin-wide drilling and logging data, which were used to divide the strata (by thickness) and identify the lithology of the sandstone and mudstone produced, thus, generating a planar graph.

\section{Results}

\section{Thermal evolution history through single-well burial}

The hydrocarbon generation history of the main source rocks in the Ordos Basin was simulated by Genex hydrocarbon generation model (as illustrated). The simulation revealed that, prior to the Late Triassic, the basin's geothermal fields were stable. Since the evolution of hydrocarbon generation from organic matter was controlled by plutonic metamorphism, little hydrocarbon was generated during this period, as the organic matter in the source rocks was at an immature stage. During the Early-Middle Jurassic, the source rocks began to cross the thresholds required for early hydrocarbon generation, as successive deposition of strata and local tectonic thermal events provided the necessary heat and pressure. By the end of the Jurassic and the beginning of the Cretaceous, the generation of hydrocarbons increased rapidly due to abnormally high paleo-geothermal fields. At the end of the Late Jurassic, oil expulsion began in the southwest portion of the basin, with oil generation and expulsion peaking during the Early Cretaceous. By the end of the Early Cretaceous, hydrocarbon generation and expulsion reached rates as high as at any point in Earth's history. After the Early Cretaceous, the basin began to experience uplift and the abnormally high paleo-geothermal fields returned to normal conditions, so hydrocarbon generation effectively grounds to a halt (Fig. 4).

In summary, the hydrocarbon generation and expulsion evolution in the Mesozoic group can be divided into two main stages: a period of strong oil generation and expulsion in the Early Cretaceous, and a period of oil and gas preservation since the Late Cretaceous.

\section{Planar paleo-tectonic characteristics of the Chang-8 at the end of the Middle Jurassic}

Around the end of the Middle Jurassic, the Chang- 8 bottom structure evolved into a tectonic pattern with high elevations in the south and southwest, and low elevations in the north and northwest. The southeast portion of the basin revealed three large swell belts that trended in a NW-SE direction, among which the southeast and southwest swells were larger than the south-central one (Fig. 5).

\section{Planar paleo-tectonic characteristics of the main oil reservoirs (Chang- 8 and Chang- 6 ) at the end of the Early Cretaceous}

The Ordos Basin experienced a large number of hydrocarbon generation periods around the end of the Early Cretaceous period. Consequently, we focused on the paleo-tectonic characteristics of the target strata during this period when determining the oil reservoir distribution rules.

At the end of the Early Cretaceous, the Chang- 8 bottom structure was broadly characterized by a tectonic pattern of high elevations in the northeast and east, and low elevations in the southwest and west. The tectonic movement had clearly reversed since the end of the Middle Jurassic. On the whole, there were four small and large swell belts that converged toward in the northwest region of the basin. The three swell belts in the central and southern parts spread in a NW-SE direction, while the one in the north spread in an $\mathrm{E}-\mathrm{W}$ direction (Fig. 6).

The Chang- 6 bottom structure inherited the same tectonic pattern of sags and swells present in the Chang- 8 bottom, as described above, at the end of the Early Cretaceous (Fig. 7).

\section{Planar paleo-tectonic characteristics of the Chang-8 at present}

The modern Chang- 8 bottom structure is broadly characterized by a single swell and single sag. The swell belt and sag area are distributed in the southeast and west of the basin, respectively, between which there is a gentle slope zone (Fig. 8). 
Fig. 4 Single-well burial history and hydrocarbon generation history restoration of Yt_ 1 well

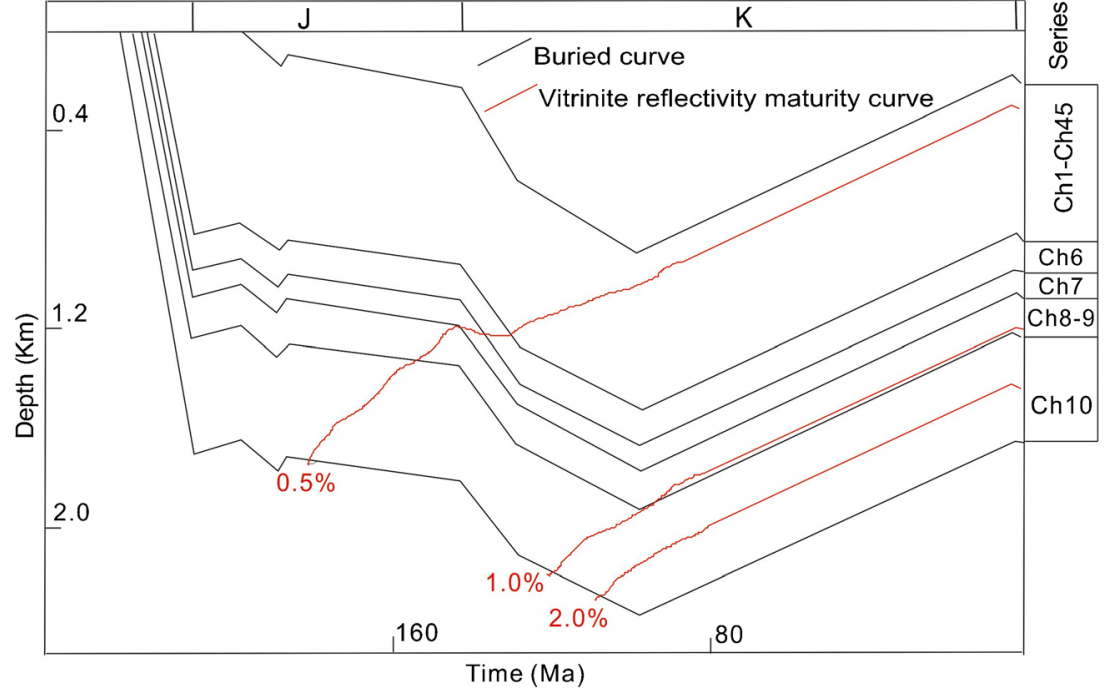

\section{Paleo-tectonic evolution characteristics of the drilling formation profile}

We have illustrated the paleo-tectonic evolution characteristics of the stratigraphic section with the dz3456-x1035 well-tie section as an example. At its greatest burial depth (Early Cretaceous), the amplitude and scope of the large anticlinal structure present in Well Area w47-x12 were equivalent to those in the earlier period (Middle Jurassic).
The tectonic evolution of the dz3456-x1035 well-tie section showed that a large anticline with a maximum undulation of approximately $200 \mathrm{~m}$ had developed in Well Area w47-x41 during the Middle Jurassic hydrocarbon generation period (Fig. 9(c)). The range of the large anticlinal structure at its maximum burial depth increased slightly during Late Cretaceous (Fig. 9(b)). Today, the formation generally provides a monocline background, and the local development slightly uplifts during the period (Fig. 9(a)).
Fig. 5 Structural morphology of Chang- 8 Member bottom at the end of the middle Jurassic and reservoir distribution of the Ordos Basin, China

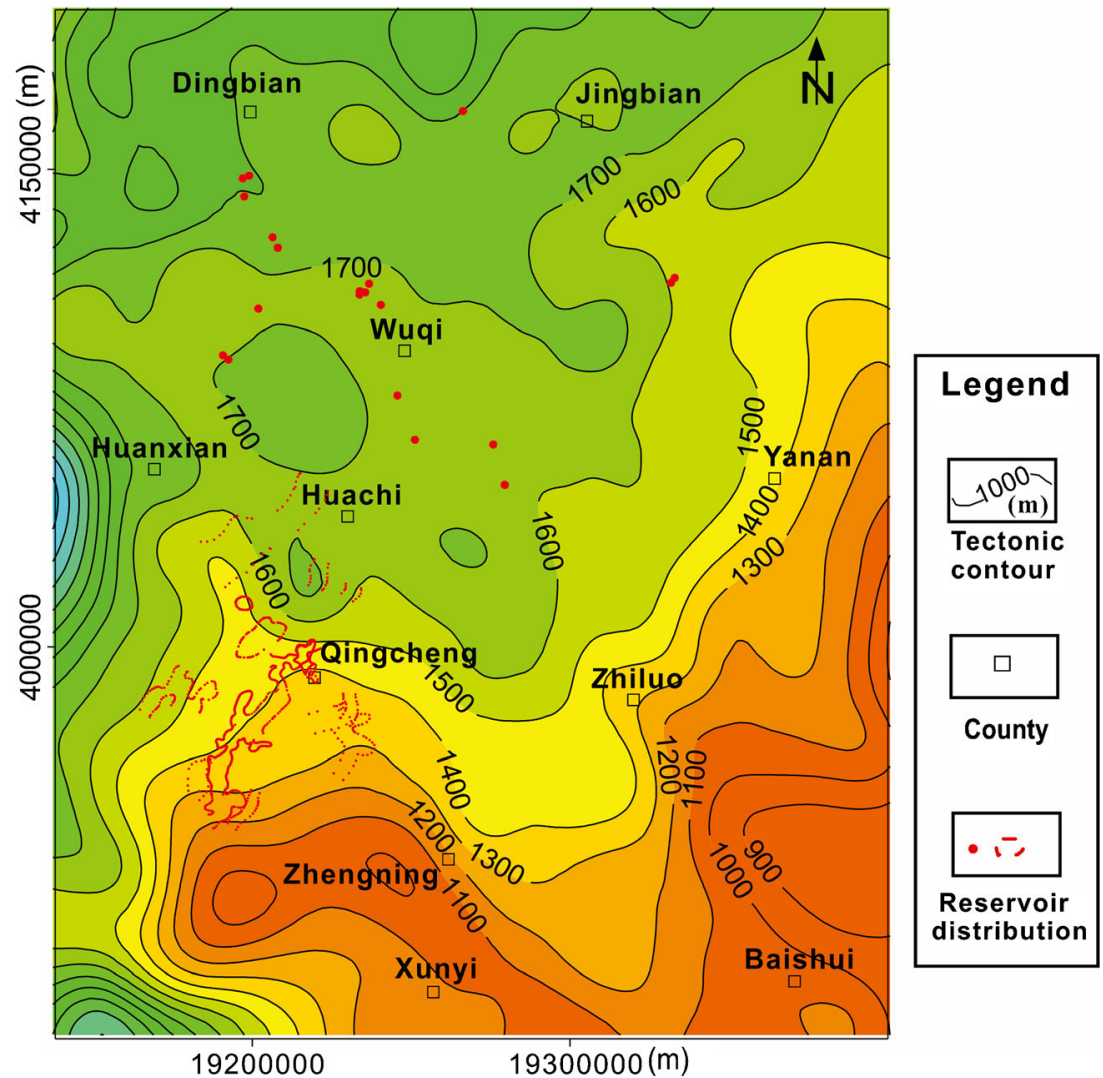


Fig. 6 Structural morphology of Chang-8 Member bottom at the end of the Early Cretaceous and reservoir distribution of Ordos Basin, China

Fig. 7 Structural morphology of Chang-6 Member bottom at the end of the Early Cretaceous and reservoir distribution of Ordos Basin, China

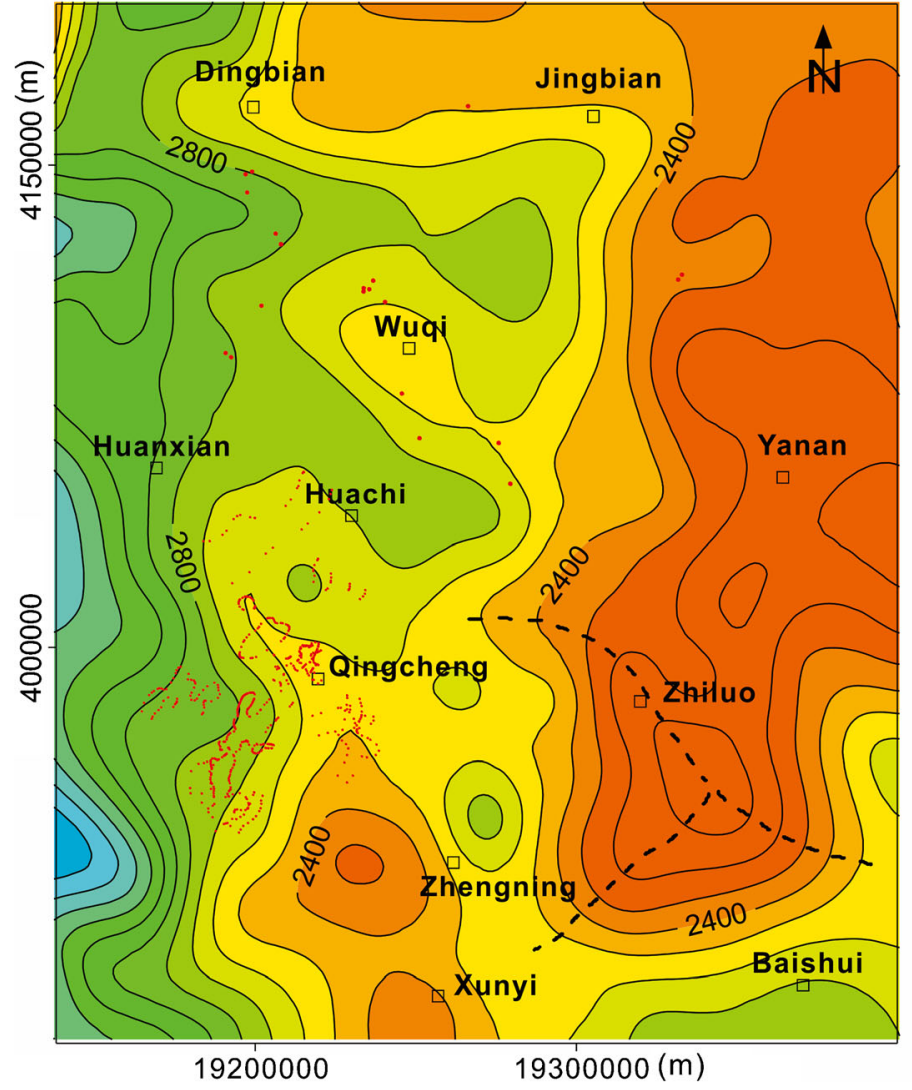

\section{Legend}

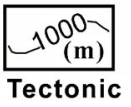
contour

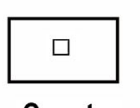

County

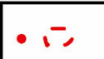

Reservoir distribution

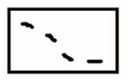

Tectonic

- ridges

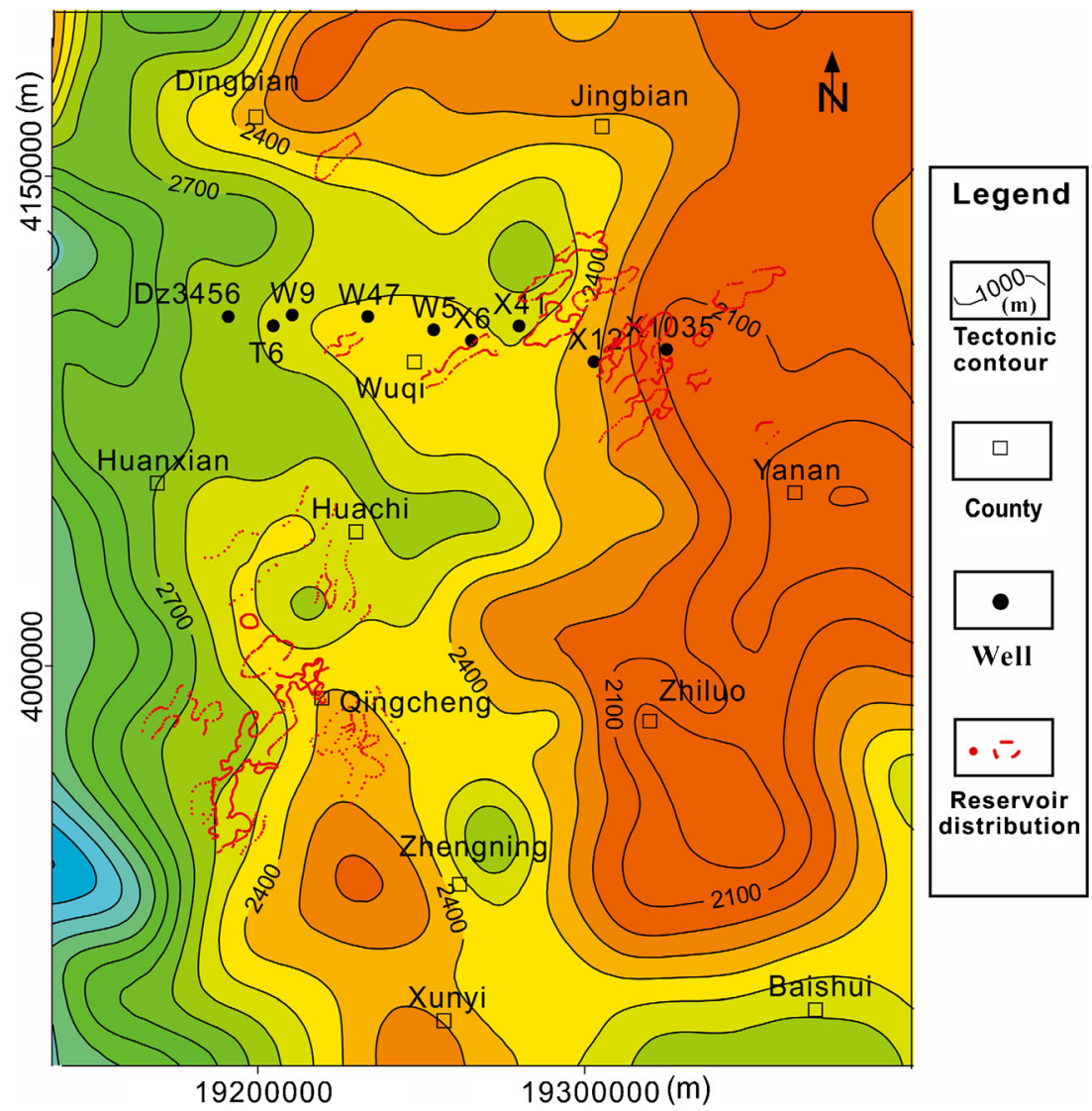


Fig. 8 Structural morphology of current Chang-8 Member bottom and reservoir distribution of Ordos Basin, China

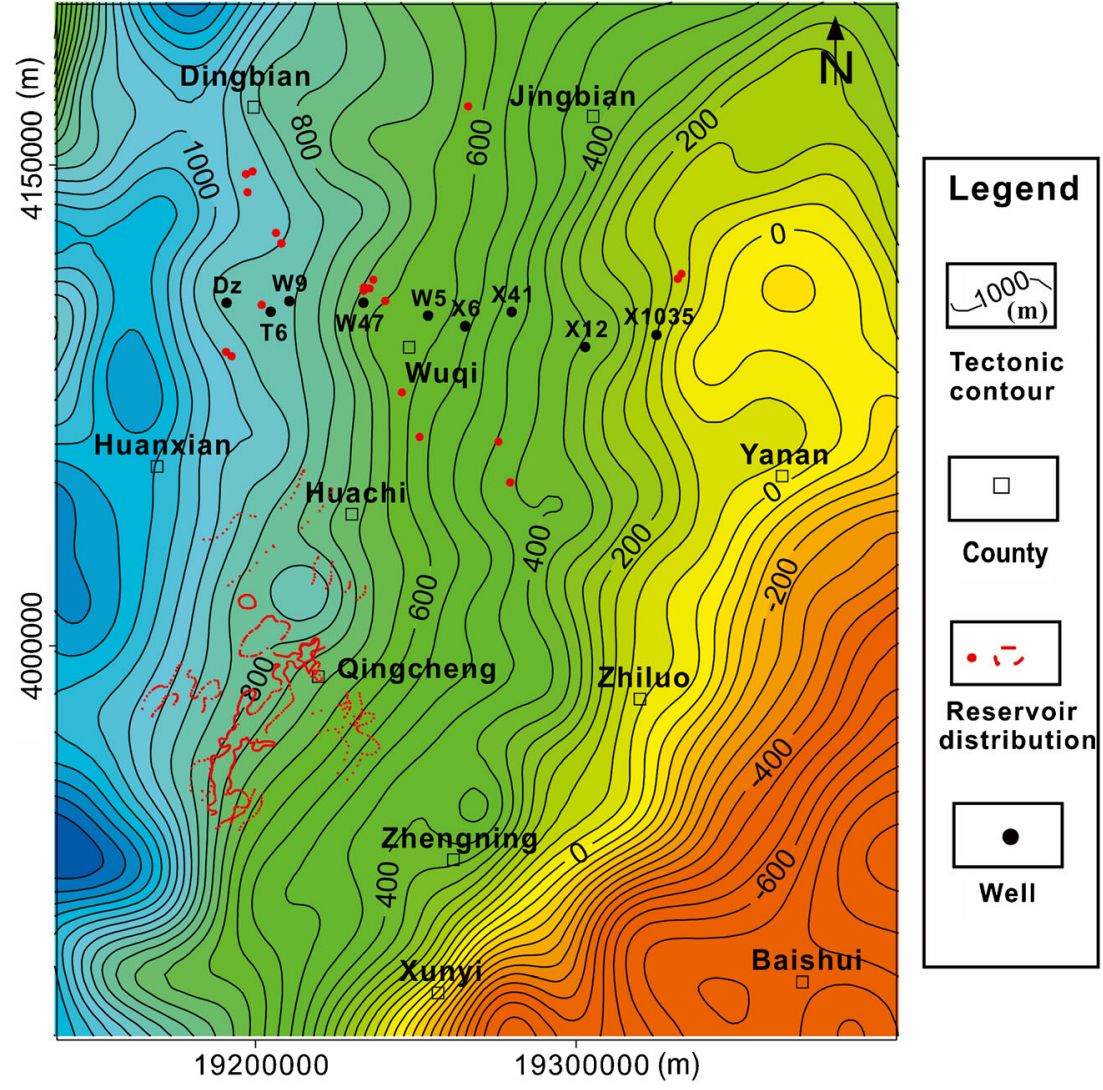

\section{Distribution of overpressure between the Chang-7 and Chang-8 strata}

The main hydrocarbon-generating geological formation in the Ordos Basin is the oil shale section at the bottom of the Chang-7 Formation. For the oil produced by the Chang-7 hydrocarbon-generating formation to migrate into the Chang-8 Formation to collect in the Chang-8 reservoir, downward migration forces were necessary. This would require an overpressure difference between Chang- 7 and Chang- 8 greater than zero. For the Chang- 6 reservoir, upward migration forces were necessary, indicating that the overpressure difference between Chang-7 and Chang- 6 was greater than 0 .

The planar distribution characteristics of the overpressure difference between Chang-7 and Chang- 8 indicate that, in the northwest and southwest of the basin, the overpressure difference was relatively large, between $6 \mathrm{MPa}$ and $20 \mathrm{MPa}$, with an average of around $10 \mathrm{MPa}$. The zones with the highest overpressure differences were most favorable for the Chang-7 oil source to migrate down to the Chang-7 Formation (Fig. 10).

\section{Distribution of the sand:ground ratio in the Chang-8 member}

Within the Chang- 8 member, zones with high sandstone:formation ratios are zonally distributed in a generally NW-SE direction (Fig. 11), indicating that the sediments mainly come from the northeast and southwest of the basin. Our results show that the Chang- 8 reservoir is composed of areas with both high and low sandstone:formation ratios. Recent studies suggest that high-quality reservoirs, including turbidite sand bodies, may be formed during the sedimentation stage of the background area of paleo-slopes.

\section{Discussion}

\section{Distribution of oil reservoirs in the gentle slope zone of the target formation during the hydrocarbon generation period}

The Chang- 8 and Chang- 6 reservoirs are both currently associated with gentle slope zones with a background of paleouplift tectonics. The Chang- 8 reservoir is mainly distributed in the southwest of the Ordos Basin, while the Chang- 6 reservoir is mainly distributed in the northeast and southwest of the basin. This demonstrates the importance of paleo-tectonic characteristics during the hydrocarbon generation period in determining the distribution of oil reservoirs. However, the differences in the distributions of the Chang- 8 and Chang- 6 reservoirs also indicate that other factors played important roles in determining tight oil accumulation in the Ordos 

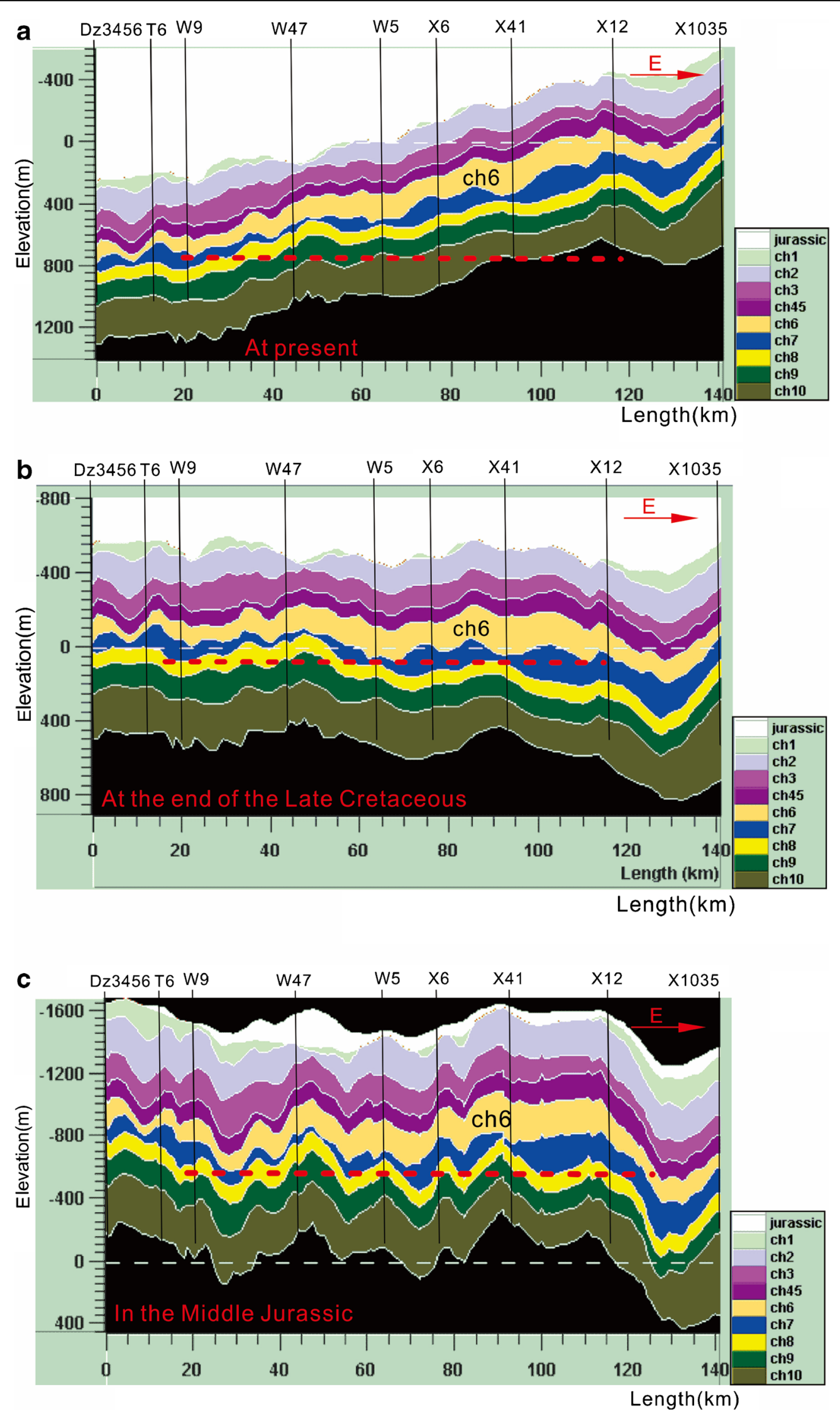
Fig. 10 Distribution characteristics of overpressure between Chang- 7 and Chang- 8 strata and tectonic uplift of Chang- 8 of the Late Cretaceous in the Ordos Basin, China

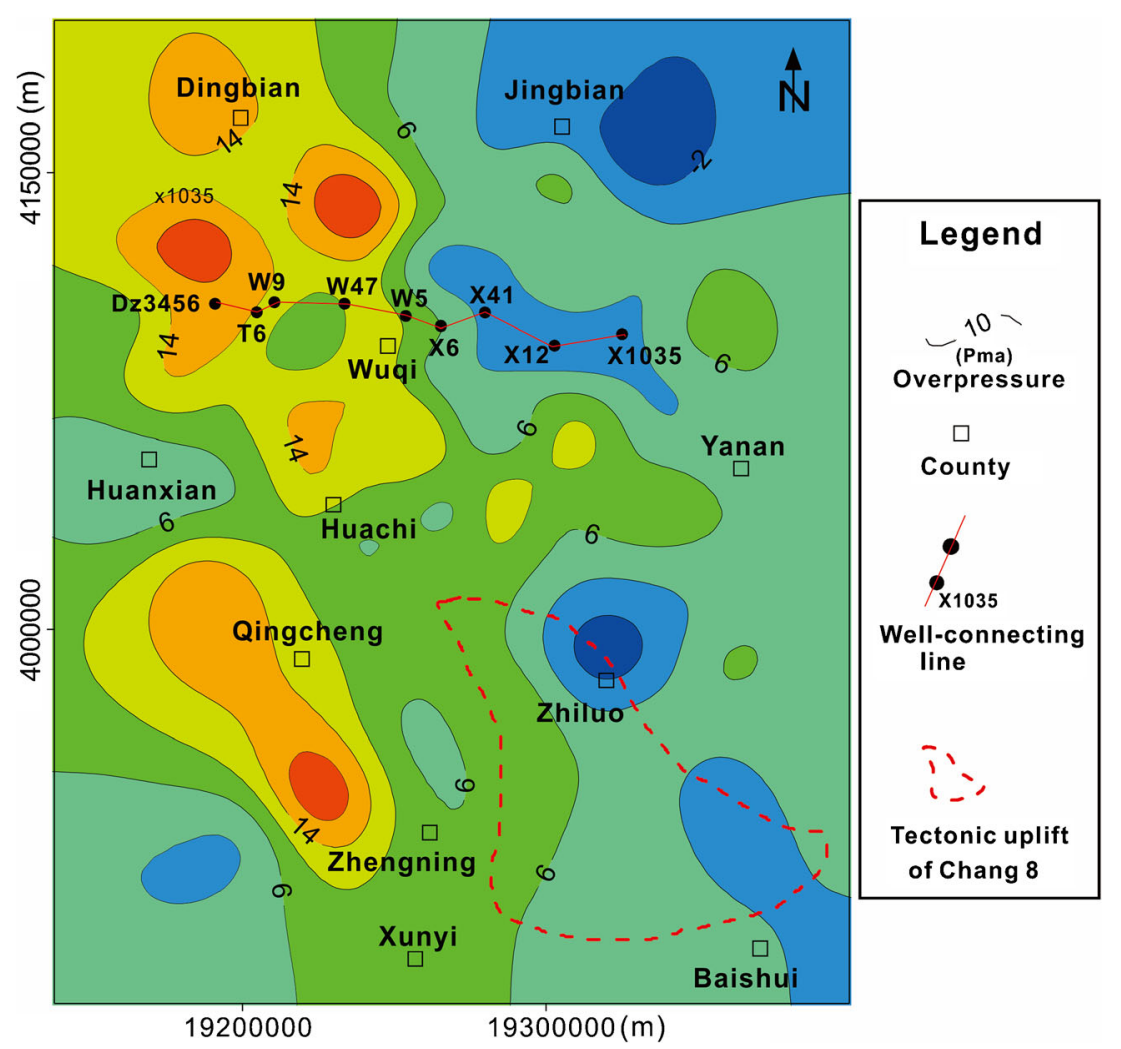

Basin. For example, oil migration, accumulation dynamics, and reservoir conditions must be considered, even as they were subject to the control constraints of the paleo-tectonic background of the region during hydrocarbon generation.
However, when considering the entire situation, both the Chang- 6 and Chang- 8 tight oil reservoirs are distributed in favorable areas in the paleo-structure during the hydrocarbon generation period (paleo-uplift, paleo-slope, etc.).
Fig. 11 Distribution of the sandground ratio in the Chang- 8 member in a favorable area where tectonic and overpressure overlap in the Ordos Basin, China

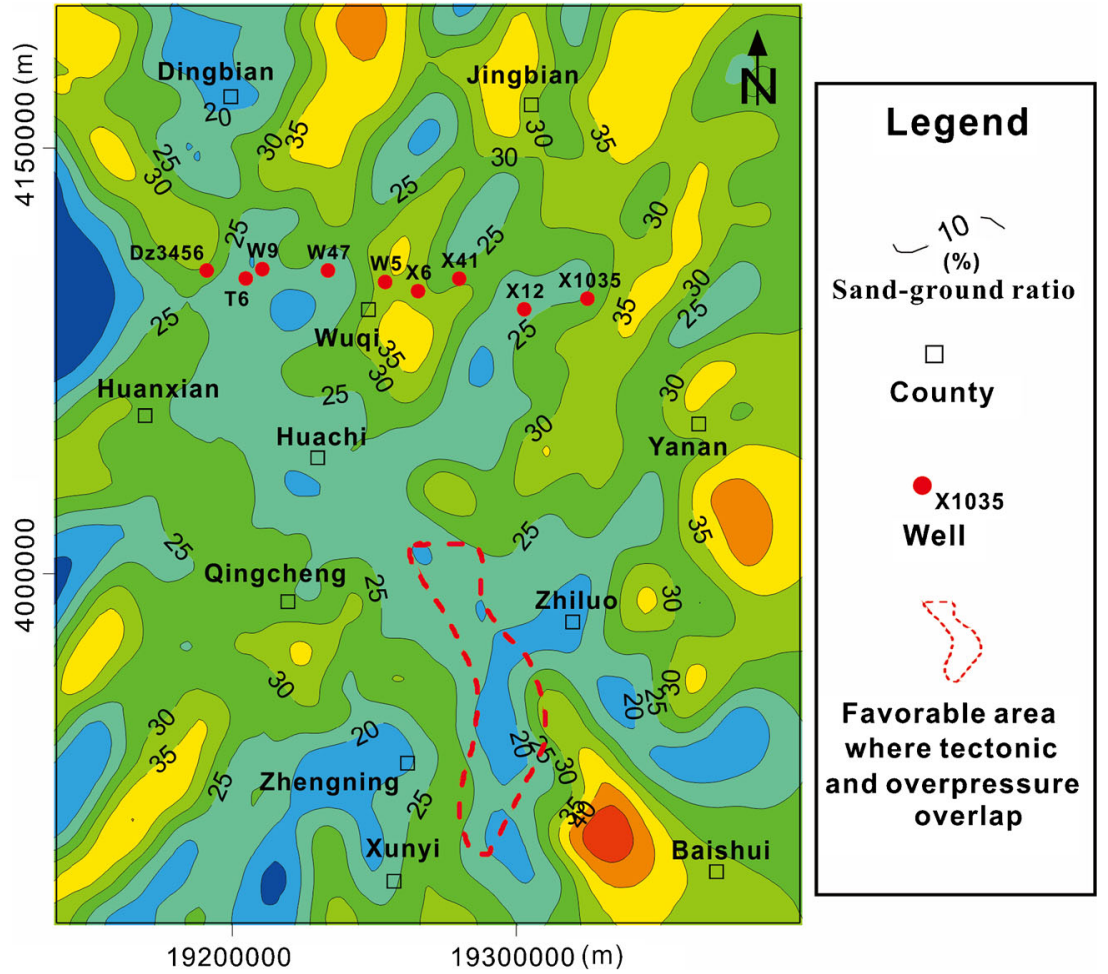


Recent studies suggest that high-quality reservoir conditions, including turbidite sand bodies, are one of the major reservoir types for the Chang- 8 reservoir, with its background of paleo-slopes.

\section{Gentle slope zones during the hydrocarbon generation period as a tectonic background for the formation of high-quality tight oil reservoirs}

The presence of high-quality reservoir conditions, as seen in the Ordos Basin, is one of the basic geological conditions for tight oil accumulation. However, certain structural conditions are also necessary for the formation of high-quality tight oil reservoirs. The edge of a depocenter (or subsag), the foreslope of a paleo-highland, and the edge of a paleo-uplift zone in a lake basin are examples of structural conditions that commonly encourage the formation of high-quality reservoirs. However, this knowledge did not attract extensive attention to the Ordos Basin until the past few years. Prior to this study, research on lake basin bottom configuration characteristics, especially quantitative research, was very weak. The reconstruction of the lake basin bottom configurations had been based on traditional sedimentary facies analysis, which outlines the shape of the lake basin bottom. For a lake basin characterized by sags in a stable craton like the Mesozoic Ordos Basin, it has been difficult to fill in important gaps in our knowledge, such as the characteristics of its paleostructural morphology and depositional slope-break zones during the hydrocarbon generation period. Most efforts have been hampered by their reliance on the stratigraphic filling structure and configuration revealed by the current lithostratigraphic unit, as well as the monotonous, nearparallel stratigraphic structure reflected by seismic data. This also made it difficult to fully understand the inner relationship between paleo-tectonics and reservoir distribution. The basin simulation technique that we have used provided an efficient way to quantify the characteristics of the lake basin bottom configuration. Future research that explores the relationship between lake basin bottom configuration and high-quality reservoir development, or the genesis and distribution of highquality reservoirs in general, can utilize this approach (Yang et al. 2015; Clavera-Gispert et al. 2017).

\section{Effective allocation of the entrapment-migration and accumulation dynamics-reservoir}

Breakthroughs in the Ordos Basin were first made during the exploration of the Chang- 8 reservoir in the southwest portion of the basin. The Chang- 8 reservoir is mainly distributed in the southwest of the Huachi-Qingcheng area. The exploration in this area benefited from the discovery of the Chang- 8 highquality reservoirs (turbidites) in the deep lake area. Recently, scattered commercial oil wells were also established in the
Chang- 8 member in the Dingbian-Wuqi area, and this has emerged as a new exploration area for the Chang- 8 reservoir. Figure 7 shows that Chang- 8 commercial-scale oil flows were drawn from Well Area dz3456-w5. In Fig. 8(b), the dz3456w5 well-tie section shows that a large, wide, and gentle anticline structure developed there during the hydrocarbon generation period. Figure 9 shows the dz3456-w5 well-tie line, where the overpressure difference between the Chang-7 and Chang- 8 formations is large. Figure 10 shows that the sandstone:formation ratio of the dz3456-w5 well-tie line is moderately low. Due to the influence of favorable paleotectonics (the large anticline structure) existing in the Chang8 Formation during the hydrocarbon generation period, as well as the high overpressure difference between Chang-7 and Chang-8, we would expect to obtain commercial-grade oil flows from the Chang- 8 Formation, wherever the sandstone:formation ratio is moderately low. The Chang-7 hydrocarbon-generating formation was not considered as a variable in this analysis because basin exploration has already established that the hydrocarbon supply in the basin as a whole was not a limiting factor.

The strata of the current Yanchang Formation present as a westward-dipping monocline with a dense reservoir lithology. This has stifled further the exploration of oil reservoirs in the Yanchang Formation in the past. The results of this study demonstrate that models of the paleo-anticlinal structural setting during the high-volume hydrocarbon generation period in the Yanchang Formation can effectively predict the tight oil distribution zones in the Ordos Basin. This model accounts for the control exerted by the setting and other reservoir-forming conditions (e.g., downward migration and accumulation dynamics and reservoir parameters).

\section{Geological and causal mechanisms in hydrocarbon accumulation}

We have ascertained the fundamental hydrocarbon generation conditions for tight oil in the Ordos Basin; however, the effective allocation of hydrocarbon source rocks and other accumulation factors during the accumulation period will need to be the focus of future studies. As we have with the bottom geomorphology of a lake basin, researchers should pay attention to the important role of structural factors in the accumulation of tight oils. This makes it possible to directly discover and evaluate the "sweet spot" zones in tight oils.

Previous studies have identified two major factors that control the formation of "sweet spots": the maturity of the deposit, which largely controls the distribution of liquid hydrocarbons, and the definite geostructural background and fluid mobility of the liquid hydrocarbons (Yang et al. 2015). The latter is advantageous to the long-term accumulation of hydrocarbons and the development of natural fractures, and has 
garnered the most attention under the current economic and technical conditions at home and abroad.

To inform specific exploration practices, areas with a paleo-tectonic background like that developed in the hydrocarbon generation stage of the Chang-8 should be the priority target areas. When combined with detections of other reservoir-forming geological conditions, this would be a feasible exploration idea and method.

\section{The difference between Chang- 8 and Chang- 6 oil reservoir distributions}

This study has demonstrated that the Chang- 8 and Chang-6 reservoirs were controlled by paleo-tectonics during their hydrocarbon generation periods, but their distributions are different. According to preliminary geological studies, in addition to favorable paleo-tectonics during the hydrocarbon generation period, it seems that the formation pressure difference with the oil-producing Chang-7 was more crucial for the Chang-8 reservoir than for the Chang- 6 . It is preferentially located in areas with a low sandstone:formation ratio, suggesting that a higher pressure difference would have been necessary for greater infiltration into high sandstone:formation ratio areas.

The Chang-6 member, with its high sandstone:formation ratio, is mainly distributed in the northeast of the basin, indicating that the sediments mainly came from the northeast. Reservoir conditions seem to have been critical for the Chang-6 reservoir.

\section{Tight oil exploration methods based on paleo-tectonics during hydrocarbon generation period}

The morphologic features of the bottom sag and swell structures during hydrocarbon generation show that the bottom swell structure (nose-shaped uplift) is often inherited and plays a decisive role in the subsequent formation of large reservoirs. During the hydrocarbon generation period, the distribution of large oilfields is controlled by large nose-shaped uplift, whereas present-day tectonic conditions have little relationship with oil reservoir distribution. The paleo-tectonic features of the target formation during the hydrocarbon generation period have obvious controlling effects on reservoir distribution.

The lake basin bottom configuration during hydrocarbon accumulation controls the formation and distribution of large, tight oil reservoirs. Specifically, tight oil will tend to be distributed in paleo-slope and paleo-uplift areas of the lake basin during the accumulation period. This fully demonstrates that high-quality reservoir formation conditions are available under those geomorphological conditions. Additionally, the source-reservoir configurations and subsequent diagenetic environments in those regions tend to be superior, which is important for the development of tight reservoirs. We are proposing a standardized approach to the exploration of tight oil resources in the Ordos Basin and similar regions.

To illustrate our proposed approach, we will take Chang- 8 as an example. Because the basin was at its maximum burial depth at the end of the Early Cretaceous period (Fig. 4), when the thermal evolution of the source rocks was at its maximum and the source rocks were experiencing their greatest period of hydrocarbon generation, the stratigraphic paleo-structure at this time was the most representative; therefore, we will use it in our analysis. The four steps of our proposed method, and their application to the Chang- 8 , are described below:

Step 1: Analysis of paleo-tectonic characteristics during the hydrocarbon generation period. Identify the high point line position of the paleo-swell and the bottom position of the paleo-swell structure, based on all paleo-swell structure information during the hydrocarbon generation period (Fig. 6).

Step 2: Identification of paleo-slopes and paleo-uplifts during the hydrocarbon generation period. Identify the areas of the swell structure that are favorable for oil production, according to the slope zone on both sides of the paleo-swell high point line.

Step 3: Determination of the source-reservoir-migrationaccumulation configuration. Identify the favorable migration and accumulation areas according to the overlap between the favorable area of the swell structure and a map of interlayer pressure differences (Fig. 10). For example, in the favorable area of the uplift structure, the Chang-7 and Chang- 8 strata with high overpressure conditions were favorable areas for migration and accumulation.

Step 4: Establishment of a favorable tight oil distribution area. Identify the favorable sedimentary facies areas that feature overlap between the favorable migration and accumulation areas and the sedimentary facies map (such as a sandstone:formation ratio map). The range of this favorable sedimentary facies area represents the favorable exploration area identified by this approach (Fig. 11).

\section{Conclusions}

1. At the end of the Late Jurassic and the Early Cretaceous, the quantity of generated hydrocarbons in the Ordos Basin increased rapidly under the action of abnormally high paleo-geothermal fields. Oil expulsion began in the southwest of the basin in the Late Jurassic, and oil generation and expulsion peaked during the Early Cretaceous. The favorable paleo-tectonic zones (paleo-uplifts and paleoslopes) present during each stage of the hydrocarbon generation period represent potentially favorable areas for exploration of tight oil resources. 
2. The morphologic features of the bottom sag and swell structures during the hydrocarbon generation period show that the bottom swell structure (nose-shaped uplift) was inherited and played a decisive role in the subsequent formation of large reservoirs. During the hydrocarbon generation period, the distribution of large oilfields was controlled by large nose-shaped uplift, while present-day tectonic conditions have little bearing on oil reservoir distribution or quality. The paleo-tectonic features of the target formation during the hydrocarbon generation period have obvious controlling effects on reservoir distribution.

3. The lake basin bottom configuration during hydrocarbon accumulation controlled the formation and distribution of large tight oil reservoirs. Specifically, tight oil was distributed in paleo-slope and paleo-uplift areas of the lake basin during the accumulation period. This demonstrates that high-quality reservoir formation conditions were available in this area. It also shows that there were suitable source-reservoir configurations and, subsequently, better diagenetic environments in the area, which are important for the development of tight reservoirs.

4. We proposed a four-step method for the identification of favorable areas for reservoir exploration based on multiple factors (e.g., deposition, hydrocarbon-generating layer, and interlayer pressure differences) from a large number of paleo-swell structures during the hydrocarbon generation period. We described their application to our study area to help guide productive exploration in the Ordos Basin and similar regions.

Acknowledgements This research has been support by the Nature Science Basic Research Plan in Shaanxi province of China(2019JM-359)

Open Access This article is distributed under the terms of the Creative Commons Attribution 4.0 International License (http:// creativecommons.org/licenses/by/4.0/), which permits unrestricted use, distribution, and reproduction in any medium, provided you give appropriate credit to the original author(s) and the source, provide a link to the Creative Commons license, and indicate if changes were made.

\section{References}

Cai NZ, Zhi Y, Lian HH, Ru KZ, Jing WC, Song TW, Sen HL, Qiu LG, She JW, Deng HL (2015) Geological characteristics and "sweet area" evaluation for tight oil. Pet Sci 12(04):606-617

Clavera-Gispert R, Gratacós Ò, Carmona A, Tolosana-Delgado R (2017) Process-based forward numerical ecological modeling for carbonate sedimentary basins. Comput Geosci 21(3):373-391

Guo JA, Pang JG, Wang GC, Hou LW, Chen QH, Cao HX (2010) Lake basin evolution and petroleum accumulation of Late Triassic Yanchang Formation in Ordos Basin. Glob Geol 291(2):277-283

He C, Ji LM, Su A, Liu Y, Li JF, Wu YD, Zhang MZ (2017) Relationship between hydrothermal sedimentation process and source rock development in the Yanchang Formation in southern Ordos Basin. Earth Sci Front 24(06):277-285

Lei JJ, Chen SJ, Lu JG, Li Y (2017) Comparison on geochemical characteristics between oil shale and black mudstone of Yanchang formation Chang 7 in the Erdos Basin, China. Pet Sci Technol 35(19): $1925-1930$

Li W, Wen ZG (2017) Characteristics of fine-grained sediments from the 7th member of the Yanchang Formation in the Southwestern Ordos Basin. Acta Geol Sin (5): 1120-1129

Liu F, Zhu XM, Li Y, Xu LM, Niu XB, Zhu SF, Liang XW, Xue MG, He JC (2015) Sedimentary characteristics and facies model of gravity flow deposits of Late Triassic Yanchang Formation in southwestern Ordos Basin, NW China. Pet Explor Dev 42(5):633-645

Luo XR, Wang ZN, Lei YH, Hu CZ (2016) Heterogeneity characteristics and accumulation model of ultra-low permeability sandstone reservoirs: a case study of the lower part of Yanchang Formation in the western Ordos Basin, China. Acta Pet Sin (z1): 87-98

Ren Z, Yu Q, Cui J, Qi K, Chen Z, Cao Z, Yang P (2017) Thermal history and its controls on oil and gas of the Ordos Basin. Earth Sci Front (China University oI Ueosciences (Beijing); Peking University) 24(03):137-148

Tong Y, Mukerji T (2017) Generalized sensitivity analysis study in basin and petroleum system modeling, case study on Piceance Basin, Colorado. J Pet Sci Eng 149(2017): 772-781

Xu ZJ, Liu LF, Wang TG, Wu KJ, Gao XY, Dou WC, Xiao F, Zhang N, Song XP, Ji HT (2017) Application of fluid inclusions to the charging process of the lacustrine tight oil reservoir in the Triassic Yanchang Formation in the Ordos Basin. China J Pet Sci Eng 149(149):40-55

Yang H, Liu X, Zhang C, Han T, Hui X (2007) The main controlling factors and distribution of low permeability lithologic reservoirs of Triassic Yanchang Formation in Ordos Basin. Lithologic Reservoirs 19(03): $1-6$

Yang H, Fu J, He H, Liu X, Zhang Z, Deng X (2012) Formation and distribution of large low-permeability lithologic oil regions in Huaqing Ordos Basin. Pet Explor Dev 39(06):641-648

Yang H, Zhong DK, Yao JL, Liu XY, Ma SY, Pan LL (2013a) Pore genetic types and their controlling factors in sandstone reservoir of Yanchang Formation in Longdong Area Ordos Basin. Earth Sci Front 20(2): 69-76

Yang W, Liu G, Liu X, Feng Y, Du Y, Cheng D (2013b) The accumulation mechanism and accumulation models of oil in low permeability reservoir of Yanchang Formation in Longdong Area, Ordos Basin. Earth Sci Front (China University oI Ueosciences (Beijing); Peking University) 20(2):132-139

Yang Z, Hou LH, Tao SZ, Cui JW, Wu ST, Lin SH, Pan SQ (2015) Formation conditions and "sweet spot" evaluation of tight oil and shale oil. Pet Explor Dev 42(05):555-565

Zhang Y, Bao Z, Zhao Y, Jiang L, Gong F (2017) Diagenesis and its controls on reservoir properties and hydrocarbon potential in tight sandstone: a case study from the Upper Triassic Chang 7 oil group of Yanchang Formation, Ordos Basin, China. Arab J Geosci (2017)10: 234

Zhao JX, Chen HD, Xiang F (2003) The possibility of rebuilding paleogeomorphology before basin deposition by high-resolution sequence stratigraphy. J Chengdu Univ Technol 30(1): 76-81

Zhao J, Yang X, Wu F, Shi B (2006) Controlling of uplifts on the Triassic petroleum accumulation and distribution in North Shaanxi Slope, Ordos Basin. Acta Geol Sin 80(5):648-655

Zhu S, Zhu X, Chen J, Yang Z, Jia Y, Cui H (2018) Diagenetic differences in tight sandstone reservoirs in two delta fronts: an example from the Chang 4 and 5 members of the Yanchang Formation in the Longdong area, Ordos Basin, China. Arab J Geosci (2018)11:715 